\title{
The Epidemiology and Economics of Spinal Cord Injury
}

\author{
S. L. Stover, M.D., and P. R. Fine, Ph.D., M.S.P.H. \\ Department of Rehabilitation Medicine, University of Alabama, Birmingham, \\ Alabama 35294, U.S.A.
}

\section{Incidence and prevalence}

The incidence of spinal cord injury (SCI) varies according to source, however, reports considered to be most accurate indicate that the annual rate is between $30 \cdot 0$ and $32 \cdot 1$ new spinal cord injuries per million persons at risk in the U.S.A. (DeVivo et al., 1980; Kraus et al., 1975). DeVivo, et al. (1980), used the mathematical relationship between incidence and duration to re-estimate the prevalence of SCI, calculating the rate to be approximately 906 per million. This figure is nearly $50^{\circ}$ o greater than that estimated by Kurtzke (1975) who based his calculations on the length of median post-injury survival; a less precise statistic in light of that which is known today.

\section{Age, sex and race}

In the U.S.A., SCIs occur most frequently in persons between 15 and 20 years of age. According to the National SCI Database maintained by the Department of Rehabilitation Medicine at the University of Alabama at Birmingham, the mean age at injury is 29.7 years, the median age is 25 years and the mode (i.e. the most frequent age at injury) is 19 years (Stover and Fine, 1986). Reported differences in age distribution are believed to reflect a myriad of non-comparable data collection strategies. The National SCI Database confirms that SCI occurs more frequently among males than among females (a 4:1 ratio) and that the average, annual race-specific incidence rates for SCI are slightly higher for blacks than whites, a finding consistent with the higher accidental death rate observed among blacks (Accident Facts, 1983).

\section{Etiology}

A review of the $10000+$ cases documented in the National SCI database confirms that in the U.S.A., as in virtually all other industrialised countries, most spinal cord injuries result from motor vehicle crashes $(47 \cdot 7 \%)$ followed by falls $\left(20 \cdot 8^{\circ}{ }_{0}\right)$, acts of violence-gunshot wounds and stabbings $(14.6 \%)$ and sporting- 
related activities $(14 \cdot 2 \%)$ (Table I). As expected, there are statistically significant relationships between etiology and factors such as age, sex, race and geography (Fine et al., 1979).

Table I Leading Causes of Spinal Cord Injury

\begin{tabular}{lr}
\hline Cause & $0_{0}^{\circ}$ \\
\hline 1. Motor vehicle accidents & $47 \cdot 7$ \\
2. Falls & $20 \cdot 8$ \\
3. Acts of violence & $14 \cdot 6$ \\
4. Sports & $14 \cdot 2$ \\
5. Other & $2 \cdot 7$ \\
\hline
\end{tabular}

\section{Neurological level and extent of lesion}

In the National SCI Database, quadriplegics were slightly more common than paraplegics $\left(52^{\circ}{ }_{0}\right.$ vs $\left.48^{\circ}{ }_{0}\right)$. In fact, neurologically incomplete quadriplegics ranked first at time of admission $\left(28^{\circ}{ }_{0}\right)$, followed by complete paraplegics $(26 \%)$, complete quadriplegics $\left(24^{\circ}{ }_{0}\right)$ and incomplete paraplegics $\left(18^{\circ}{ }_{0}\right)$. A review of neuro-level and extent (i.e. the neurological completeness of lesion) trends over more than 10 years revealed a decline in the proportion of neurologically complete quads. There is ample evidence suggesting this 'shift' is due, in large part, to markedly improved emergency medical management procedures developed and implemented during the past decade (Thomas, 1982).

\section{Survival}

The overall cumulative 10 year survival rate for the entire National Database is slightly more than $86^{\circ}{ }_{0}$. For patients in this database, the statistical probability of dying was determined to be greatest during the first post-injury year, declining somewhat thereafter. Patients between 10 and 19 years of age had the highest 10 year survival rate. Not surprisingly, 10 year survival rates declined substantially after age 29 , so that by ages 60 to 69 , little more than half of the patients survive 10 years. With regard to the cumulative 10 year survival by neurological level and extent of lesion, incomplete paraplegics have the highest 10 year survival rate, followed by complete paraplegics, incomplete quadriplegics and complete quadriplegics. The ratio of observed to expected deaths in the absence of SCI are $6 \cdot 19,6 \cdot 85,10 \cdot 29$ and $20 \cdot 05$ for the four neuro-categories, respectively.

\section{Life expectancy}

Life expectancies for SCI patients aged 20, 40 and 60 by neuro-category were calculated using a method described by Smart and Sanders (1976) and appear in Table II. The estimates in the table are lower than those reported previously because they include patients who die prior to discharge whereas earlier estimates have been based on patients discharged alive after completing extensive rehabilitation programmes. Since the risk of dying is greatest during the 
Table II Life Expectancies (In Years)

\begin{tabular}{lccccc}
\hline & & \multicolumn{4}{c}{ Neuro-category } \\
\cline { 2 - 6 } Age at injury & No injury & PI & PC & QI & QC \\
\hline 20 years & $55 \cdot 4$ & $33 \cdot 2$ & $32 \cdot 1$ & $27 \cdot 4$ & $20 \cdot 1$ \\
40 Years & $36 \cdot 8$ & $18 \cdot 0$ & $17 \cdot 1$ & $13 \cdot 8$ & $9 \cdot 3$ \\
60 Years & $20 \cdot 0$ & $6 \cdot 5$ & $5 \cdot 9$ & $4 \cdot 2$ & $1 \cdot 9$ \\
\hline
\end{tabular}

first post-injury year, patients who survive this period have significantly longer life expectancies.

\section{Cause of death}

Recently, workers at the National Spinal Cord Injury Statistical Center completed a retrospective study of 5131 patients from the National Database who sustained their spinal cord injuries between 1973 and 1980. When follow-up was terminated, 461 patients $\left(9^{\circ}{ }_{0}\right)$ had died. Overall, the leading causes of death were pneumonia, accidents and suicides. The highest ratios of actual to expected deaths were for septicaemia, pneumonia and pulmonary emboli. Pneumonia was the leading cause of death for patients at least 55 years of age, non-whites and quadriplegics. Accidents and suicides were the leading cause of death for patients less than 55 years of age, whites and paraplegics.

Causes of death by age group are shown in Table III. Accidents and suicides were the leading cause of death for patients less than 55 years of age. Septicaemia had the highest ratio of actual-to-expected deaths for all age groups, followed by pulmonary emboli for patients less than 55 years of age, and pneumonia for patients at least 55 years of age. Accidents, suicides and cancer were the leading causes of death among paraplegics, whereas pneumonia was the leading cause of death among quadriplegics. When considering causes of death by length of postinjury survival, these data revealed the ratios of expected to actual deaths were

Table III Cause of Death by Age

\begin{tabular}{|c|c|c|c|c|c|c|c|c|c|}
\hline \multirow[b]{2}{*}{ Cause of death } & \multicolumn{3}{|c|}{ Age $<25$} & \multicolumn{3}{|c|}{ Age $25-54$} & \multicolumn{3}{|c|}{ Age $>54$} \\
\hline & $\begin{array}{l}\text { Actual } \\
\text { deaths }\end{array}$ & $\begin{array}{c}\text { Expected } \\
\text { deaths }\end{array}$ & Ratio & $\begin{array}{l}\text { Actual } \\
\text { deaths }\end{array}$ & $\begin{array}{c}\text { Expected } \\
\text { deaths }\end{array}$ & Ratio & $\begin{array}{l}\text { Actual } \\
\text { deaths }\end{array}$ & $\begin{array}{c}\text { Expected } \\
\text { deaths }\end{array}$ & Ratio \\
\hline Septicaemia & 5 & .02 & 250.0 & 15 & $\cdot 10$ & $150 \cdot 0$ & 11 & $\cdot 15$ & $73 \cdot 3$ \\
\hline Cancer & 2 & 63 & $3 \cdot 2$ & 5 & $5 \cdot 49$ & 0.9 & 19 & $10 \cdot 88$ & $1 \cdot 7$ \\
\hline Ischemic heart disease & 1 & .04 & $25 \cdot 0$ & 7 & $5 \cdot 71$ & $1 \cdot 2$ & 17 & $16 \cdot 12$ & $1 \cdot 1$ \\
\hline Other heart disease & 10 & $\cdot 17$ & $58 \cdot 8$ & 13 & .89 & $14 \cdot 6$ & 17 & 1.43 & $11 \cdot 9$ \\
\hline Cerebrovascular disease & 4 & $\cdot 10$ & $40 \cdot 0$ & 8 & $1 \cdot 18$ & $6 \cdot 8$ & 8 & 3.95 & $2 \cdot 0$ \\
\hline Diseases of arteries & 2 & .03 & $66 \cdot 7$ & 2 & $\cdot 24$ & $8 \cdot 3$ & 3 & $1 \cdot 14$ & $2 \cdot 6$ \\
\hline \multicolumn{10}{|l|}{ Venous thrombosis and } \\
\hline Flu and pneumonia & 11 & $\cdot 12$ & $91 \cdot 7$ & 27 & .60 & $45 \cdot 0$ & 28 & 1.03 & $27 \cdot 2$ \\
\hline Other respiratory disease & 2 & .08 & $25 \cdot 0$ & 9 & .47 & $19 \cdot 1$ & 4 & $1 \cdot 79$ & $2 \cdot 2$ \\
\hline Diseases of digestive system & 5 & .05 & $100 \cdot 0$ & 8 & $1 \cdot 88$ & $4 \cdot 3$ & 2 & $1 \cdot 08$ & 1.9 \\
\hline Diseases of urinary system & 3 & .05 & 60.0 & 4 & $\cdot 30$ & $13 \cdot 3$ & 6 & .59 & $10 \cdot 2$ \\
\hline \multicolumn{10}{|l|}{ Symptoms and ill-defined } \\
\hline conditions & 10 & $\cdot 24$ & 41.7 & 15 & $\cdot 87$ & $17 \cdot 2$ & 13 & $\cdot 69$ & $18 \cdot 8$ \\
\hline Accidents and suicides & 18 & $8 \cdot 18$ & 2.2 & 30 & $8 \cdot 21$ & $3 \cdot 7$ & 2 & 1.54 & $1 \cdot 3$ \\
\hline Residual & 5 & $2 \cdot 58$ & 1.9 & 7 & $6 \cdot 95$ & $1 \cdot 0$ & 5 & 3.56 & $1 \cdot 4$ \\
\hline Unknown & 18 & & & 30 & & & 31 & & \\
\hline
\end{tabular}


highest during the first month post-injury for all causes except cancer, accidents and suicides. During the first month post-injury the ratio was highest for pulmonary emboli, followed by septicaemia, pneumonia and an ICDA category designated as symptoms and ill-defined conditions. The leading cause during the first 6 months post-injury was 'other heart disease', whereas accidents and suicides were the leading causes of death more than 6 months post-injury. While renal failure and other urinary tract complications were traditionally acknowledged to be the overall leading cause(s) of death until the mid-1970s, recent data reflect a significant decline in their role as the primary killer of SCI patients (Geisler et al., 1983; Hackler, 1977; Le and Price, 1982; Young et al., 1982).

\section{Economics of spinal cord injury}

Between 1974 and 1984, the average length of stay (ALOS) for all patients admitted to a federally sponsored SCI Care System within 24 hours of injury declined $27 \%$, from 137 to 100 days. There was a $23 \%$ reduction in ALOS among quadriplegics (from 150 to 116 days) and a $31 \%$ reduction in ALOS among paraplegics (from 122 to 84 days). Subsequently, the United States Consumer Price Index was used to adjust documented hospital charges to 1985 dollars. Despite reductions in average lengths of stay, average billed hospital charges for all SCI patients increased from $\$ 41300$ in 1973 to $\$ 67300$ in 1984. A similar trend was noted among quadriplegics with average adjusted hospital charges increasing from $\$ 46100$ in 1973 to $\$ 80500$ in 1984 . Average adjusted hospital charges for paraplegics peaked at $\$ 58800$ in 1983 . For reference purposes, it has been established that hospital charges reflect approximately $80 \%$ of total initial costs of care in the U.S.A. (Young, 1978).

\section{References}

ACCIDENT FACTS 1983 National Safety Council, Chicago, Illinois

DeVivo MJ, Fine PR, MAETz HM, et al. 1980 Prevalence of spinal cord injury: A re-estimation employing life table techniques. Archives of Neurology 37:707-708

Fine PR, Kuhlemeier KV, DeVivo MJ, et al. 1979 Spinal Cord Injury: An epidemiologic perspective. Paraplegia 17:237-250

GEISLER WO, JouSSE AT, WYNNE-JONEs M, et al. 1983 Survival in traumatic spinal cord injury. Paraplegia 21:364-373

HACKLER RH 1977 A 25-year prospective mortality study in the spinal cord injured patient: comparison with the long-term living paraplegic. Fournal of Urology 117:486-488

KraUs JF, Franti CE, RIGGINS RS, et al. 1975 Incidence of traumatic spinal cord lesions. Fournal of Chronic Disease 28:471-492

KURTZKE JF 1975 Epidemiology of spinal cord injury. Experimental Neurology 48:163-236

LE CT, PrICE M 1982 Survival from spinal cord injury. Fournal of Chronic Disease 35:487-492

SMART CN, SANDERS CR 1976 The Costs of Motor Vehicle Related Spinal Cord Injuries. Insurance Institute for Highway Safety, Washington, D.C., pp. 33-43

StOver SL, FINE PR (eds) 1986 Spinal Cord Injury: The Facts and Figures. The National Spinal Cord Injury Statistical Center, University of Alabama at Birmingham, Birmingham, Alabama

Thomas JP 1982 Inaugural lecture of the G. Heiner Sell distinguished lectureship. Presented at the Eighth Annual Scientific Meeting of the American Spinal Injury Association, New York, New York, April 9

YouNG JS 1978 Initial hospitalization and rehabilitation costs of spinal cord injury. Orthopedic Clinics of North America 9:263-270

Young JS, Burns PE, Bowen AM et al. 1982 Spinal Cord Injury Statistics: Experience of Regional Model Spinal Cord Injury Systems. Good Samaritan Medical Center, Phoenix, Arizona 